SJ Quinney College of Law, University of Utah Utah Law Digital Commons

$12-2020$

A Historical Note on the Assignment of Pesticide Common Names

Jorge L. Contreras

Follow this and additional works at: https://dc.law.utah.edu/scholarship

Part of the Intellectual Property Law Commons 


\title{
A HISTORICAL NOTE ON THE ASSIGNMENT OF PESTICIDE COMMON NAMES
}

\author{
Jorge L. Contreras \\ University of Utah
}

\section{Introduction}

Thousands of pesticides, herbicides, and related chemical products are used today to control disease-bearing insect populations and enable large-scale agricultural production that feeds much of the world. Yet, little is generally known about these products. This short note traces the history of one small but important aspect of this industry- the assignment of common names to pesticides and related products.

\section{Background-Common Names for Pharmaceuticals}

Every drug on the market today generally has three different names: a chemical name, a generic or nonproprietary name, and a proprietary or brand name. While drug manufacturers seek to differentiate themselves and enhance their brands via advertising, packaging, and other means, ${ }^{1}$ it is important for public health and safety purposes to have a consistent set of nonproprietary names that all manufacturers can use to refer to drugs having the same active ingredients. For example, Advil ${ }^{\circledR}$ and Motrin $^{\circledR}$ are well-known brands of the same pain medication-ibuprofen-which bears the chemical name (RS)-2-(4-(2methylpropyl)phenyl)propanoic acid. ${ }^{2}$

Pharmaceutical chemical names are assigned by the International Union of Pure and Applied Chemistry (IUPAC), an international scientific and standardization body founded in $1919 .{ }^{3}$ In addition to chemical nomenclature, the IUPAC assigns names to newly discovered elements and develops standardized units of measure, among other things. Because the chemical name is too complex for routine usage, most physicians, pharmacists, and consumers refer to a drug either by its brand name (e.g., Advil ${ }^{\circledR}$ ) or, when referring to a class of drugs, by its generic name (e.g., ibuprofen).

Generic drug names are created under the International Nonproprietary Names (INN) program run by the World Health Organization (WHO). ${ }^{4}$ The WHO INN program plays an important role in the approval of generic drug names in particular countries, including the United States. In the United States, generic drug names are assigned by the United States Adopted Name Council (USAN Council), a joint undertaking of the American Medical Association (AMA), the United States Pharmacopeia (USP), and the American Pharmacists Association (APhA), in cooperation with the US Food and Drug Administration (FDA). ${ }^{5}$

\section{Pesticide Common Names}

Like pharmaceutical products, pesticides each have a chemical name, a common or generic name, and in some cases, a brand or proprietary name. For example, DuPont's Lannate ${ }^{\circledR}$ insecticide targeted at leaf-eating pests has the common name Methomyl and the chemical name S-methyl N-[(methylcarbamoyl)oxy]thioacetimidate. The Bayer (Monsanto) herbicide 
Roundup ${ }^{\circledR}$ — the subject of recent high-profile tort litigation-contains the active ingredient isopropylamine salt of glyphosate (generally referred to as glyphosate), having the chemical name $\mathrm{N}$-(phosphonomethyl)glycine.

In the United States, the regulation and oversight of pest control products and programs was historically shared by a number of Federal agencies, including the Public Health Service, the Department of Agriculture, and the Departments of War and the Navy. ${ }^{6}$ The large-scale eradication and control of disease-bearing insects was pioneered by the Army Corps of Engineers and Public Health Service in the early twentieth century to support US military activity in tropical locations such as Cuba and Panama. ${ }^{7}$ A Federal Interdepartmental Committee on Pest Control was formed in 1946 to help these agencies to coordinate their activities, research, and public communication. ${ }^{8}$ Among the Committee's first activities was "the adoption of coined names for insecticides" to be used in lieu of the complex and lengthy chemical names in product labeling and other communications. ${ }^{9}$

\section{ASA/ANSI Committee K-62}

In 1954, the task of developing common names for pesticides was handed off to the American Standards Association (ASA), ${ }^{10}$ a private sector body that led the US efforts on standardization in a variety of industrial sectors. ${ }^{11}$ A committee (ASA Committee K-62) was formed that year comprising the representatives of governmental agencies and medical and scientific societies, under the sponsorship of the US Department of Agriculture (USDA). ${ }^{12}$ Significantly, both the US Patent Office and the USDA were included as members of Committee K-62. ${ }^{13}$ The Committee charter included the development and approval of common names for herbicides, insecticides, fungicides, rodenticides, and other chemicals. ${ }^{14}$ Committee K-62 also coordinated with the International Standardization Organization (ISO), the Geneva-based organization that established international standards, through its Technical Committee 81 (ISO/TC 81) for the development of common names for pesticides and other agrochemicals. ${ }^{15}$

In 1969, ASA became the American National Standards Institute (ANSI), which continued the work of Committee K-62. ${ }^{16}$ Committee K-62 participated actively in ISO/TC 81, and in 1983, it hosted a plenary meeting of the ISO committee at the USDA's facility in Beltsville, Maryland.

\section{American Standard K62.1}

In 1956, ASA Committee K-62 approved a procedure for the proposal and approval of common names for pest control chemicals, which it published as American Standard K62.11956. ${ }^{17}$ This procedure was intended "to make possible the adoption of common names readily acceptable and usable by all interested groups, while guarding against confusion with existing common or proprietary names and against improper use in the future."18 Under this procedure, new common names for pesticides would be proposed to ASA by a sponsor-either the product manufacturer or another organization having an interest in the product. ${ }^{19}$ Proposed names not only had to comply with a number of technical criteria, ${ }^{20}$ but also had to be free of potential trademark claims. In particular, the sponsor of a proposed name was required in Section 3.5 to certify to ASA that: 
a search has been conducted and findings are submitted to verify the absence of conflicts with existing domestic trademarks or names for other chemicals or products. Should the proposed Common Name itself be trade-marked or be in apparent conflict with any domestic trade-mark or trade name, the Sponsor shall submit to the Committee a written statement from the trade-mark owner releasing the proposed Common Name for unrestricted use. ${ }^{21}$

The sponsor was thus required to represent not only that it would not claim trademark rights in an approved common name, but also that it had searched and determined either that the proposed name was not subject to competing trademark rights or that it had obtained the commitment of the holder of trademark rights permitting the use of the mark as a common pesticide name.

The form of written statement was included in Section 4.2.11 of Standard K62.1-1956:

The undersigned agrees to release and permit the use of the name '___ ' (the proposed common name) for use with respect to any product, whether or not manufactured or formulated by the undersigned, which contains a pest control chemical conforming to the description of the pest control chemical specified by ASA in an American Standard adopted and made public pursuant to this Statement.

This procedure indicates a strong interest in trademarks by the industrial members of Committee K-62, and a strong desire to keep pesticide common names free from capture by an individual manufacturer.

\section{The Shift from ANSI to ISO}

Sparked by the publication of Rachel Carson's 1962 book Silent Spring, which detailed the environmental and health risks of the synthetic pesticide dichlorodiphenyltrichloroethane (known as DDT), public concern over the safety of pesticides increased throughout the 1960s and 1970s. As a result, pesticide regulation was overhauled and expanded in the United States beginning in $1970 .^{22}$ A part of this increased regulation involved shifting oversight of the pesticide industry from the USDA to the newly formed Environmental Protection Agency (EPA). The regulatory regime imposed by EPA lengthened the pesticide product development cycle and increased the costs of regulatory compliance, resulting in a sharp decline in the number of new pesticide products registered for use in the United States. ${ }^{23}$

The result of this sea change in the US pesticide industry appears to have had several effects in the naming process for new pesticides. First, EPA, which was charged with pesticide regulation, required that the "accepted common name" of a pesticide be displayed on the product label. ${ }^{24}$ However, following the general trend of Federal agencies to shift naming authority for regulated products to the private sector, ${ }^{25}$ in 1997 EPA expressly deferred to ANSI's Committee K-62 for purposes of determining pesticide common names. ${ }^{26}$ Yet in that same year, ANSI discontinued both Committee K-62 and its participation in ISO/TC 81. 
The reasons for this disengagement appear primarily to have been financial. Funding for the Committee had been provided largely by the USDA, which no longer had primary responsibility for pesticide regulation in the United States, and EPA, subject to its own budgetary pressures, ${ }^{27}$ seemed unwilling to fill this funding gap. In addition, ANSI, which charged for copies of Standard K62.1, did not sell many copies of this standard, and, as a result, viewed it as an unprofitable product. The last version of ANSI's K62.1 naming procedure was published in 1985 , and the standard was withdrawn as inactive in $2001 .^{28}$

ANSI's withdrawal from the pesticide naming arena ceded this function largely to ISO/TC 81, which continues to operate without significant US participation. ISO/TC 81 currently has nine participating members and thirty-two observing members, none of which are from the United States. ${ }^{29}$ ISO standard 257:2018 (originally published in 1976) lays out guidelines for the development of common names for pesticides and other agrochemicals, with the goal of creating "short, distinctive, easily pronounced names, which will be common to all languages." 30 As in the old ANSI procedure, common pesticide names are generally proposed by private companies with an interest in the field and then reviewed by ISO TC/81.

Despite the migration of pesticide nomenclature to ISO, private US-based organizations continue to monitor and publish reference works and compendia of common names. For example, in the herbicide area, the Weed Science Society of America (WSSA) maintains a standing Terminology Committee (P22) and publishes the Herbicide Handbook, a compendium of herbicide data including common and scientific names. In the absence of ANSI approval of herbicide names through Committee K-62, WSSA receives information on new herbicides directly from the manufacturers, which are responsible for demonstrating that the information submitted is valid.

\section{Conclusion}

The little-known history of pesticide common names is illustrative of a few important points. First, it demonstrates the trend exhibited in many fields for the development of standards to migrate from a governmental agency to a US-based standards organization to an international standards organization. Second, it evidences the concern that many in the standards world have had over the potential capture of common names by private firms through trademark law. The anti-trademark protections built into ANSI's Standard K62.1-1956 sought to ensure that common names for pesticides and related chemical products would remain available for all manufacturers to use. With the demise of ANSI Committee K-62, direct US participation in the development of pesticide common names has gone by the wayside. Nevertheless, it appears that industry norms, as well as unofficial oversight by WSSA and other scientific bodies, have, thus far, deterred the capture of pesticide common names through trademark law. Even so, it is worth asking whether it is in the best interests of the US industry to cede this important function entirely to international oversight, and whether increased US participation in ISO may be warranted both in this area and others. 


\section{Acknowledgments}

The author thanks Timothy Gray for information about WSSA Committee P22 (Terminology), and Alan Wood and Barrie Walker for information about ANSI's participation in ISO TC/81. Research assistance by Luke Hanks is greatly appreciated.

\section{Author}

Jorge L. Contreras (jorge.contreras@law.utah.edu) is a Presidential Scholar and Professor of Law, University of Utah S.J. Quinney College of Law, J.D. (Harvard Law School), B.S.E.E., B.A. (Rice University). Before entering academia, Professor Contreras was a partner at the international law firm Wilmer Cutler Pickering Hale and Dorr LLP, where he practiced transactional and IP law in Boston, London, and Washington, DC. His research focuses, among other things, on intellectual property, technical standards, and the use, dissemination, and ownership of scientific data. He is the author of more than 100 scholarly articles and book chapters, and the editor of six books, including the Cambridge Handbook of Technical Standardization Law, two volumes $(2017,2019)$. Contreras has been quoted in the New York Times, Wall Street Journal, Economist, Washington Post, and Korea Times, and has been a guest on National Public Radio (NPR), Public Radio International (PRI), and British Broadcasting Corporation (BBC) radio shows and various televised broadcasts. His work has been cited by the US Federal Trade Commission, European Commission, and courts in the United States and Europe. The author declares no conflicts of interest.

\footnotetext{
${ }^{1}$ Proprietary drug names are often created de novo as fanciful terms (e.g., Viagra, Lipitor, Tylenol, etc.) and are thus among the strongest trademarks. For a description of the lengthy and complex process used to select proprietary names for pharmaceutical products, see, e.g., Pharmacia Corp. v. Alcon Labs., Inc., 201 F. Supp. 2d 335, 340-47 (D.N.J. 2002).

2 See WebMD, Ibuprofen Oral, https://www.webmd.com/drugs/2/drug-5166-9368/ibuprofen-oral/ibuprofenoral/details (visited Mar. 30, 2019).

${ }^{3}$ See International Union of Pure and Applied Chemistry, Who We Are, https://iupac.org/who-we-are/ (visited Mar. 30, 2019).

${ }^{4}$ World Health Org., Guidance on the Use of International Nonproprietary Names (INNs) for Pharmaceutical Substances 19 (2017).

${ }^{5}$ The USAN Council grew out of the AMA-USP Nomenclature Committee, which has been adopting common drug names since 1961. Joseph B. Jerome, Review: United States Adopted Names (USAN). Cumulative List No. 1, 1961-1962, 186 J. Am. Med. Assn. 1104 (1963). In 1964, the APhA joined this group to form the USAN Council. 21 C.F.R. 299.4(c) (2014).

${ }^{6}$ See Establishment of an Interdepartmental Committee on Pest Control, 39 J. Econ. Entomology 823, 823 (1946).

${ }^{7}$ See, e.g., David McCulloch, The Path Between the Seas 407-15 (1977).

${ }^{8}$ See Establishment of an Interdepartmental Committee, supra note 6, at 823.

${ }^{9}$ See The Interdepartmental Committee on Pest Control, 44 J. Econ. Entomology 1029, 1029 (1951).

${ }^{10}$ George W. Fiero, Report on Program of Common Names for Pesticides, 53 Trademark Rep. 553, 553 (1963).

${ }^{11}$ See Andrew L. Russell, Open Standards and the Digital Age: History, Ideology, and Networks 63 (2014).

${ }^{12}$ Fiero, supra note 10, at 553-54.

${ }^{13} I d$. at $553-54$.

${ }^{14} \mathrm{Id}$. at 554.

${ }^{15} \mathrm{Id}$. at 553.

${ }^{16}$ A search of the web store of the commercial standards vendor SAI Global (infostore.saiglobal.com) for the term ANSI K.62.1 yields 102 standards, each of which was last updated in 1997 (search conducted Apr. 1, 2019).

17 American Standards Association, American Standard K62.1-1956-American Standard Procedure for the Acceptance of an American Standard Common Name for a Pest Control Chemical (Feb. 28, 1956) (reproduced in R. Behrens et al., Terminology Committee Report: Weed Society of America, 4 Weeds 278, 284-87 (1956) [hereinafter ASA K62.1-1956].

${ }^{18}$ ASA K62.1-1956, supra note 17, at $\S 1.1$.
} 
${ }^{19} I d$. at $\$ 2.6$.

${ }^{20} I d$. at $\S \S 3.3-3.4$.

${ }^{21}$ Id. at $\S 3.5$. See also Fiero, supra note 10, at 557-59 (sample application with trademark disclosures).

${ }^{22}$ See Michael Ollinger and Jorge Fernandez-Cornejo, Innovation and Regulation in the Pesticide Industry, 27 Agricultural Resource Econ. Rev. 15, 15-17 (1998).

${ }^{23}$ See id. at 15 ("Between 1970 and 1989, as pesticide research expenditures used for health and environmental testing rose from $14 \%$ to $47 \%$ of total pesticide research spending and chemical pesticide product development time rose from seven to eleven years, the number of chemical pesticides dropped from 46 over the $1972-76$ period to 30 over the 1985-89 period. The number of new chemical pesticide registrations for vegetables and other minor crops declined from 62 over the $1972-76$ period to 15 for $1985-89 . . . ")$.

${ }^{24} 40$ CFR 156.10(g).

${ }^{25}$ Other examples of this trend can be found in common names for pharmaceuticals and synthetic fibers. See Jorge L. Contreras, Sui-Genericide, 106 Iowa L. Rev. (2021 forthcoming). On the general US agency preference for the adoption of private standards, as directed by OMB Circular A-119, see Emily S. Bremer, Government Use of Standards in the United States and Abroad in The Cambridge Handbook of Technical Standardization Law: Further Intersections of Public and Private Law 28, 32-34 (Jorge L. Contreras, ed., 2019).

${ }^{26}$ US Environmental Protection Agency, PRN 97-5: Use of Common Names for Active Ingredients on Pesticide Labeling, § IV.C, https://www.epa.gov/pesticide-registration/prn-97-5-use-common-names-active-ingredientspesticide-labeling ("EPA prefers that common names for chemicals be established through standards-setting organizations such as ANSI").

27 See Leif Frederickson et al., History of US Presidential Assaults on Modern Environmental Health Protection, 108 Am. J. Pub. Health S95 (2018) (After 1994, “Conservative congressional dominance initiated a 'slow but steady starvation' of the EPA, with budget cuts ... The agency's budget shrank even as it gained new laws and regulations to implement, with court-ordered deadlines").

${ }^{28}$ Information provided to author by ANSI Web Store supervisor via telephone (212-642-4980) on Apr. 1, 2019.

29 International Standardization Organization, ISO/TC 81, https://www.iso.org/committee/50160.html (visited Apr. 1, 2019). Interestingly, the EPA still refers to ANSI's development of pesticide common names in materials as recent as 2012. See, e.g., Environmental Protection Agency, Label Review Manual at p. 5-3 (2012) ("EPA will permit the use of common names approved by the American National Standards Institute (ANSI) in the labeling ingredients statement without the accompanying scientific chemical names").

${ }^{30}$ International Standardization Organization, ISO 257:2018, Introduction. 